\title{
Circadian Patterns of ST Elevation Myocardial Infarction in the New Millennium
}

\author{
Rajan Kanth, MD; Sunitha Ittaman, MD; and Shereif Rezkalla, MD, FACP
}

\begin{abstract}
Objective: Nearly four decades ago, a circadian pattern of acute myocardial infarction (AMI) with a peak in the early morning waking hours was described. The goal of the present study was to determine whether major changes in lifestyle and significant advances in medical therapy have altered this pattern in the intervening years.
\end{abstract}

Design: Retrospective chart review.

Setting: Tertiary care hospital in central Wisconsin.

Methods: We examined circadian patterns of ST elevation myocardial infarction (STEMI) in 519 patients diagnosed with STEMI over a 5-year period. Time of symptom onset was obtained from patient self-reports in the medical record and was recorded over 24 hours.

Results: We observed a circadian pattern of STEMI occurrence with a morning peak at approximately I I:30 AM. This pattern was highly significant in patients who were not using beta-blockers $(P<0.000 \mathrm{I})$ and had no history of diabetes $(P<0.000 \mathrm{I})$, but was otherwise absent. The circadian pattern appeared to be attenuated in patients of a younger age, female gender, or who used statins or aspirin. Peak STEMI occurrence was earlier in smokers than non-smokers.

Conclusions: Despite significant lifestyle changes and medical advances in the nearly four decades since a circadian pattern of AMI occurrence was first described, patients with STEMI had a circadian pattern of symptom onset with a morning peak. Use of beta-blockers and a history of diabetes mellitus abolished this pattern. Other modifying factors, including medications, age, and gender attenuated, but did not abolish, the circadian pattern.

Keywords: Beta-blockers; Circadian rhythm; Diabetes; Myocardial infarction

A

cute myocardial infarction (AMI) causes significant morbidity and mortality in the United States. ${ }^{1}$ Several physiological factors can trigger AMI, and a number of these factors are known to fluctuate with circadian rhythm. ${ }^{2}$ Circadian patterns of AMI were first described in 1976 by the World Health Organization Regional Office for Europe who reported a peak incidence in the onset of pain between 8:00 $\mathrm{AM}$ and 10:00 $\mathrm{AM}^{3}{ }^{3}$ Similar results were reported by the Multicenter Investigation of Limitation of Infarct Size
(MILIS) study group in $1985,{ }^{4}$ which showed a circadian pattern of AMI with peak incidence in the morning between 6:00 AM and noon. Since 1985, several other groups have demonstrated a relationship between AMI and circadian rhythm with varying patterns. ${ }^{5-17}$ Additionally, several factors have been found to modify or attenuate the circadian pattern of AMI including demographic factors, ${ }^{8,12}$ medications, $4,7,8,12,18,19$ comorbidities, ${ }^{8,12,20,21}$ and lifestyle choices. ${ }^{8,12,17}$
Corresponding Author: Shereif Rezkalla, MD, FACP; Department of Cardiology; Marshfield Clinic; 1000 North Oak Avenue; Marshfield, WI 54449; Tel: (7I5) 387-5845; Fax: (7I5) 389-5757; Email: rezkalla.shereif@ marshfieldclinic.org

\author{
Received: September 5, 2012 \\ Revised: January 9, 2013 \\ Accepted: January 16, 2013 \\ Published online ahead of print: April II, 2013
}

doi: $10.3121 / \mathrm{cmr} .2013 .1120$

Grant Funding: Financial support for this study was provided by the Seubert Endowment at the Marshfield Clinic Research Foundation 


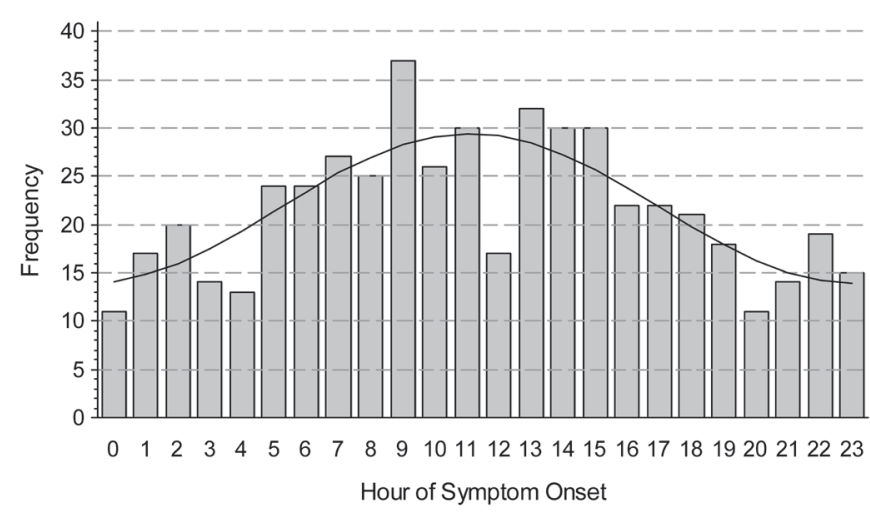

Figure 1. Observed and modeled counts by hour of STEMI symptom onset. Hour of onset was modeled using a singleperiod sine-cosine function.

In the nearly four decades since the first report of circadian patterns of AMI, lifestyles have changed significantly, and major advances in medical therapy have been made. Perhaps most notably, the rise in obesity and concurrent shift to a more sedentary lifestyle has resulted in an increase in several risk factors for cardiovascular disease and more patient prescriptions for related medications. ${ }^{22,23}$ The goal of the present study was to determine whether circadian patterns of AMI persist despite these changes and to examine potential modifying factors.

\section{Materials and Methods}

We conducted a retrospective, observational study involving 519 patients with STEMI at Ministry St. Joseph's Hospital in Marshfield, Wisconsin. Patient data were abstracted from the cardiovascular data registry and adjudicated by review of individual patient records in the electronic medical record (EMR). The protocol was approved by the Marshfield Clinic Institutional Review Board.

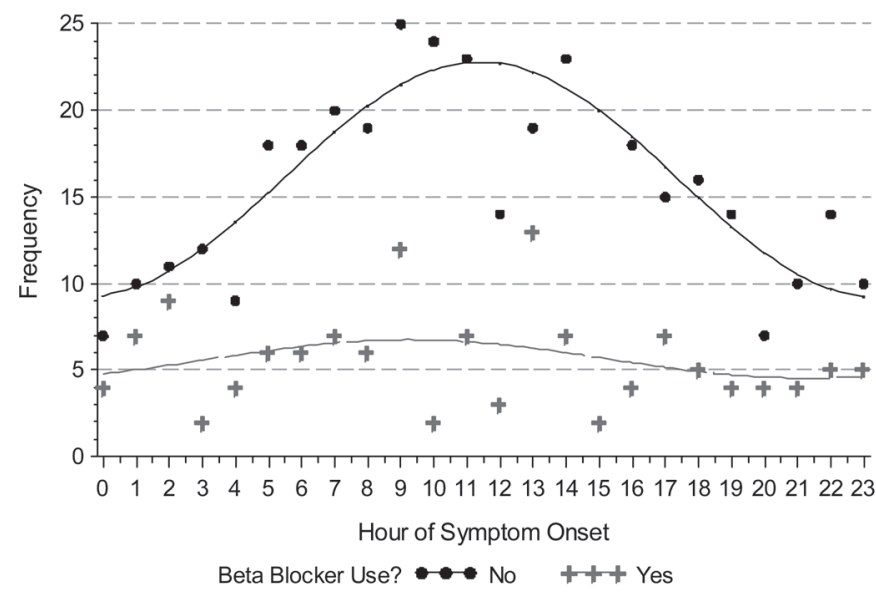

Figure 2. Time of STEMI symptom onset in patients who did and did not use $\beta$-blockers. $\beta$-blocker use abolishes the circadian pattern. Observed (points) and modeled (line) counts are shown by hour of STEMI symptom onset. Hour of onset was modeled using a single-period sine-cosine function.
Study Population

The patient population included male and female patients ages 18 years and older who presented with chest pain between January 1, 2006 and December 31, 2010 and were subsequently diagnosed with STEMI. STEMI diagnosis was based on electrocardiogram (EKG) criteria including ST-segment elevation of $\geq 1 \mathrm{~mm}(0.1 \mathrm{mV})$ in 2 or more adjacent limb leads or $>2 \mathrm{~mm}$ in the precordial leads and positive cardiac biomarkers (troponin/CK-MB). Patients with insufficient or unclear data regarding symptom onset or $<1$ year of follow-up were excluded.

\section{Data Collection}

Time of onset of chest pain and symptoms of myocardial infarction were obtained from patient self-reports recorded by emergency medical service (EMS) or emergency department staff. For 11 patients who presented with non-specific symptoms, time of symptom onset was not recorded and time of call to EMS or EKG time was noted instead. Additional data collected included information about onset of chest pain, age, gender, past medical history (diabetes mellitus, congestive heart failure $[\mathrm{CHF}]$, dyslipidemia, hypertension), medications (aspirin, clopidogrel, beta-blockers, statins), and outcomes (death, CHF, stroke) during hospital stay and in the following year.

\section{Statistical Analyses}

Standard descriptive statistics were used to summarize important characteristics of the STEMI cohort by time period of symptom onset. Preliminary comparisons were based on Chi-square tests for frequencies and the rank sum test for continuous variables. In the primary study analyses, event frequencies were analyzed by time of onset in keeping with a circular distribution over the 24-hour clock. The Rayleigh test was used to evaluate the hypothesis of a uniform distribution of times, and the hour of onset was modeled using a singleperiod sine-cosine function (a higher period sinusoid was evaluated, but did not fit the data as well based on the adjusted $\mathrm{R}^{2}$ criterion). All analyses were conducted using SAS version 9.2 statistical software. References to statistical significance are based on the $5 \%$ level of significance $(P<0.05)$ in twosided tests.

\section{Results}

We observed a circadian pattern of STEMI incidence with onset in the late morning hours. Single-period sine-cosine modeling over the entire 24-hour period demonstrated a morning peak occurring at approximately 11:30 AM (figure 1). However, use of beta-blockers and a history of diabetes mellitus abolished this pattern. While the circadian pattern of STEMI occurrence was highly significant in patients who did not use beta-blockers $(P<0.0001)$, it was absent in those who $\operatorname{did}(P=0.4024)$ (figure 2$)$. Similarly, patients with no history of diabetes mellitus displayed a clear circadian pattern ( $\mathrm{P}$ $<0.0001)$, which was absent in diabetic patients $(P=0.3495)$ (figure 3). The circadian pattern of STEMI was similar in smokers and non-smokers, except that smokers had an 


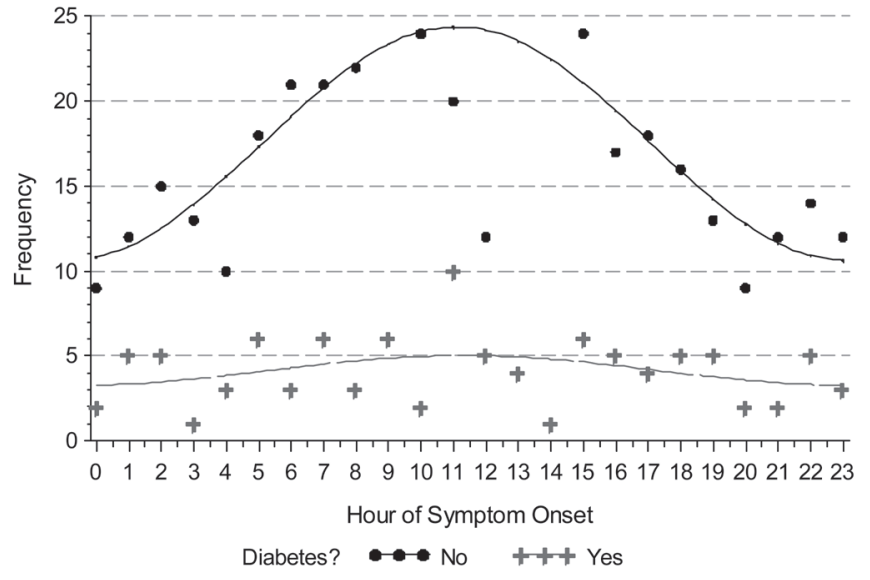

Figure 3. Observed (points) and modeled (line) time of STEMI symptom onset in patients with and without a history of diabetes mellitus. Hour of onset was modeled using a singleperiod sine-cosine function. The circadian pattern is absent in diabetic patients.

earlier peak than that of non-smokers (figure 4). Several factors were found to attenuate the circadian pattern in STEMI incidence. The circadian pattern was present, but attenuated, in patients of a younger age, female gender, or who used statins or aspirin (figure 5). No significant relationships were observed between outcomes, including death, CHF, or stroke, and time of onset of chest pain during initial hospital stay or over 1 year of follow-up. Other patient comorbidities and clinical outcomes are depicted in Table 1 and no correlation between time of symptom onset and any events were noted.

\section{Discussion}

Since the 1970s, many studies have demonstrated a circadian pattern in AMI onset with a peak occurrence in the morning. ${ }^{3-15,17,24}$ The past four decades have seen major changes in lifestyle and significant improvements in medical intervention. It is generally accepted that poor diet and a shift toward a more sedentary lifestyle have resulted in a dramatic rise in obesity in the United States and a concurrent rise in obesity-related comorbidities. ${ }^{22,23}$ Comparison of population demographics in studies of circadian rhythm and MI over time are telling of these changes. In 1989, Hjalmarson et al observed a $16 \%$ rate of obesity in study patients, ${ }^{6}$ and in 1992 Tofler et al noted an obesity rate of $13.9 \% .{ }^{9}$ By 1997 , Sayer et al observed an obesity rate of $21 \%,{ }^{12}$ consistent with the $19.1 \%$ observed in the present study. Similarly, while Tofler et al observed hypertension in $38.3 \%$ of patients in $1992,{ }^{9}$ rates had risen to $56.1 \%$ of patients in a 2010 study by Holmes et $\mathrm{al},{ }^{17}$ and $61.1 \%$ in the present study. In addition to the increase in obesity-related comorbidities, an increased utilization of cardioprotective pharmaceuticals has also been observed over time. In 1993, the American Heart Association (AHA) officially recommended use of aspirin as a therapeutic agent for the prevention of cardiovascular disease. ${ }^{25}$ We noted an increase in aspirin use from $10.8 \%$ in the 1992 study by Tofler et $\mathrm{al}^{9}$ to $13 \%$ in the 1997 study by Sayer et al, ${ }^{12}$ and $33.5 \%$ in the present study. The increase in beta-blocker usage over time appears to be even greater, with a $4.5 \%$ rate of use in the 1985 study by Muller et $\mathrm{al}^{2}{ }^{2}$ rising to approximately $17 \%$ to $18 \%$ in studies by Hjalmarson et $\mathrm{al}^{6}$ in 1989 and Tofler et $\mathrm{al}^{9}$ in 1992 , and $26.2 \%$ in the present study. In addition to changes in lifestyle and medical intervention, significant progress has also been made in the past several years in recognizing differences in symptoms of ischemic heart disease in women. ${ }^{26}$ Accordingly, the number of female subjects noted in studies over time has increased from 18.4\% in a 1989 study by Willich et al ${ }^{7}$ to $21 \%$ in 1997 by Sayer et al, ${ }^{12}$ and $31 \%$ in the present study. Our findings are consistent with those that have appeared in the literature over time, ${ }^{11,13,15,17}$ and suggest that despite major changes in lifestyle and significant improvements in medical care over the past nearly four decades, the effects of circadian rhythm on AMI occurrence have remained constant.

Several factors that are considered triggers of cardiovascular disease undergo circadian variation. ${ }^{2}$ In the morning, sympathetic activity ${ }^{10,27-29}$ and platelet aggregability increase while plasma fibrinolytic activity decreases. ${ }^{30-37}$ These changes result in altered hemostasis and an imbalance between myocardial oxygen supply and demand, potentially leading to AMI. Other changes noted in the morning, especially with assumption of the upright posture, include increased heart rate, sympathetic tone, renin activity, and plasma concentrations of cortisol, epinephrine, norepinephrine, and angiotensin II. ${ }^{9,30,32,38,39}$ Sympathetic activity may further enhance platelet aggregation, ${ }^{40}$ and cortisol may increase sensitivity of the coronary arteries to the vasoconstrictor effects of catecholamines. ${ }^{41,42}$ Increased blood viscosity and platelet aggregability in the absence of a compensatory increase in circulating tissue-type plasminogen activator activity results in an environment of relative hypercoagulability. Additionally,

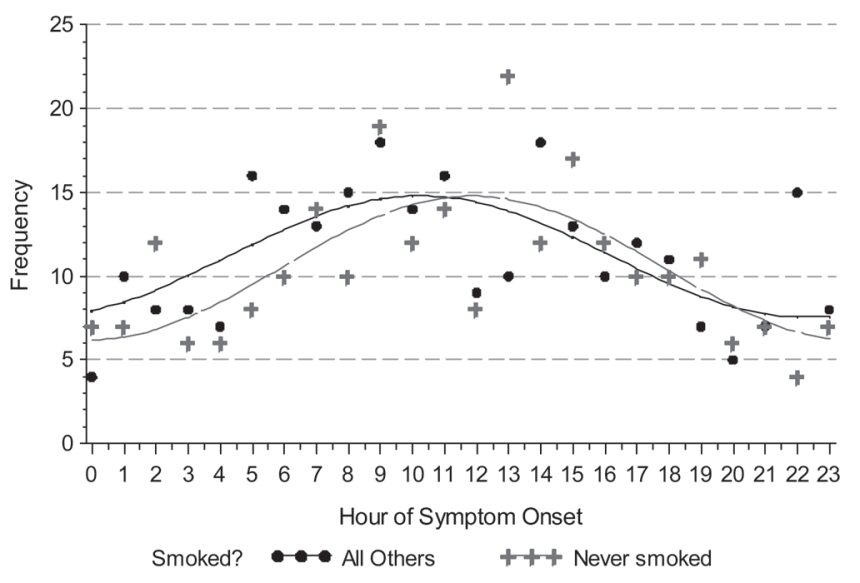

Figure 4. Observed (points) and modeled (line) time of STEMI symptom onset in patients who never smoked compared to all others. Hour of onset was modeled using a single-period sinecosine function. The morning peak in STEMI occurrence is earlier in those with a history of smoking. 

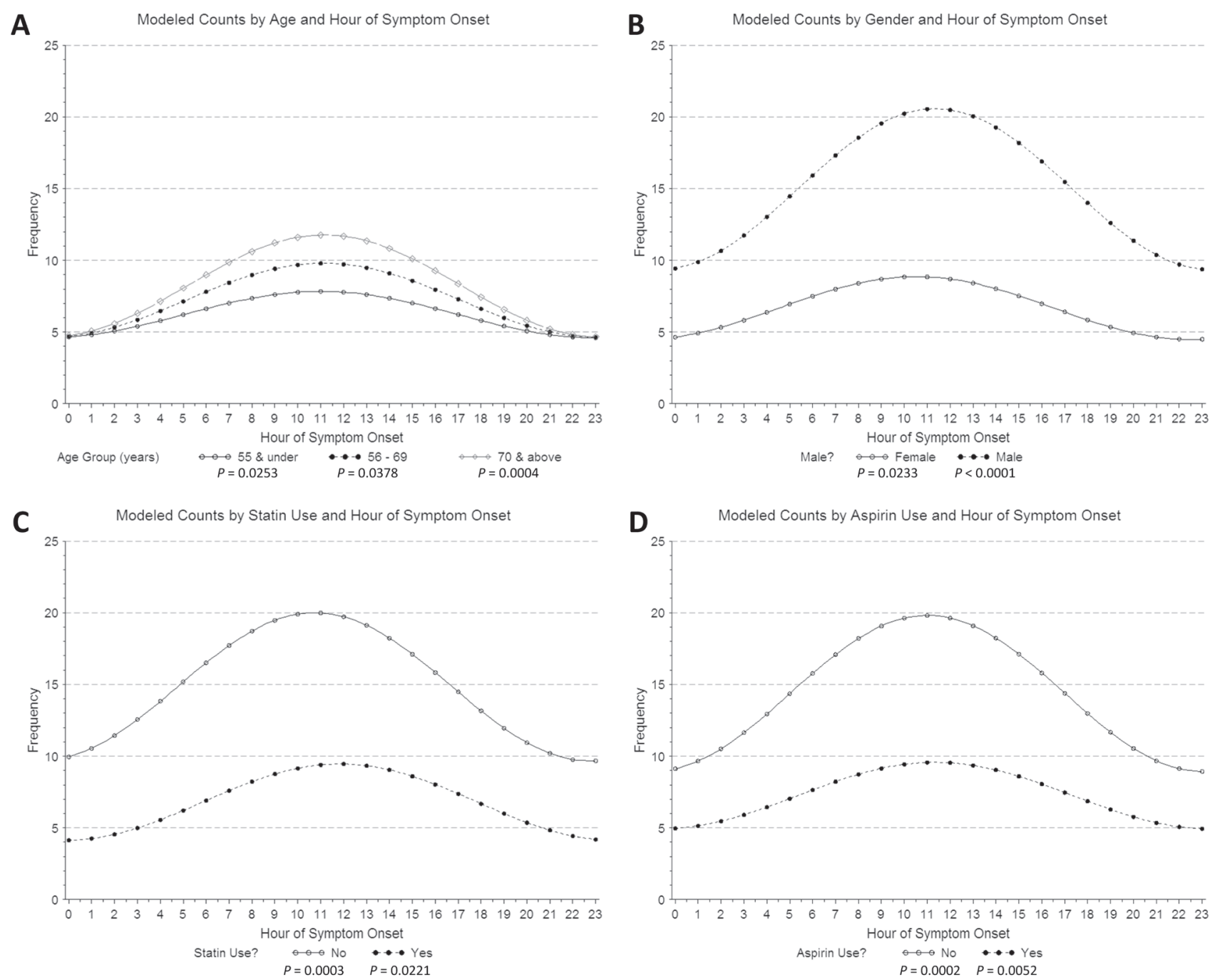

Figure 5. Time of STEMI symptom onset in patients by $(A)$ age, $(B)$ gender, and $(C)$ statin and (D) aspirin use. Hour of onset was modeled using a single-period sine-cosine function. The circadian pattern is present, but attenuated in younger, female, statin using, and aspirin using patients.

recent studies have demonstrated that clock genes in human cardiac tissue display significant time-dependent transcriptional variation with peak expression of some clock genes and trough expression of others coinciding with myocardial incidents. ${ }^{43}$ Morning hours may also represent nadir levels of some cardioprotective medications. Together, these hemostatic changes, changes in gene expression, and external triggers may create a shearing stress and cause rupture of vulnerable coronary atherosclerotic plaques in the morning, when an elevated prothrombotic state already exists. ${ }^{44-49}$

In addition to the morning peak, a secondary peak of AMI occurrence in the evening has been identified in several earlier studies..$^{4-6,10,24}$ This peak is notably absent in our study as well as in two contemporary studies published in 2007 and 2010 by Leiza et $\mathrm{al}^{15}$ and Holmes et al, ${ }^{17}$ respectively. In 1989, Muller et $\mathrm{al}^{2}$ hypothesized that the presence of this secondary evening peak was indicative of population-wide synchronization of additional triggers for AMI, similar to those identified for the morning peak, such as the evening meal. It is possible that changes in lifestyle over the past several years have contributed to a gradual loss in this peak due to a loss of population-wide synchronization of such triggers in the evening time, while synchronization upon waking still exists.

The factors that modify the circadian pattern of AMI occurrence identified in the present study are similar to those reported in the literature. ${ }^{4,7,8,12,15,17-21}$ It is interesting that while use of beta-blockers and a history of diabetes completely abolished the presence of a circadian pattern of AMI onset, other modifying factors including age, gender, statin use, and aspirin use merely attenuated the pattern. Beta-blockers are known to prevent increases in sympathetic activity, catecholamine concentrations, heart rate, blood pressure, and cardiac oxygen demand. Similarly, there may be decreased autonomic function in diabetic patients. Depression of these 
Table 1. Patient characteristics by period of symptom onset.

\begin{tabular}{|c|c|c|c|c|}
\hline & \multirow[b]{2}{*}{$\mathbf{n}$} & \multicolumn{3}{|c|}{ Time Period } \\
\hline & & 00:01 - 08:00 & 08:01-16:00 & $16: 01-24: 00$ \\
\hline Number Subjects & 519 & 158 & 224 & 137 \\
\hline Male & 359 & $66.5 \%$ & $70.5 \%$ & $70.1 \%$ \\
\hline Median Age in Years (Range) & & $64.6(29-94)$ & $63.0(32-94)$ & $63.7(26-92)$ \\
\hline Never Smoked & 251 & $45.6 \%$ & $50.4 \%$ & $48.2 \%$ \\
\hline Diabetic & 99 & $19.0 \%$ & $16.1 \%$ & $24.1 \%$ \\
\hline Hypertensive & 317 & $62.0 \%$ & $62.9 \%$ & $56.9 \%$ \\
\hline Heart Failure & 22 & $4.4 \%$ & $4.5 \%$ & $3.6 \%$ \\
\hline MI/Coronary Artery Disease & 101 & $16.5 \%$ & $17.9 \%$ & $25.5 \%$ \\
\hline Coronary Artery Bypass Graft Surgery & 115 & $24.1 \%$ & $21.4 \%$ & $21.2 \%$ \\
\hline Stroke & 37 & $7.6 \%$ & $7.6 \%$ & $5.8 \%$ \\
\hline Cardiogenic Shock & 98 & $16.5 \%$ & $17.0 \%$ & $24.8 \%$ \\
\hline Aspirin Users & 174 & $34.2 \%$ & $32.6 \%$ & $34.3 \%$ \\
\hline Beta-blocker Users & 135 & $29.1 \%$ & $22.8 \%$ & $27.7 \%$ \\
\hline ACE Inhibitor or ARB Users & 114 & $13.9 \%$ & $25.4 \%$ & $25.5 \%$ \\
\hline Statin Users & 163 & $26.6 \%$ & $32.6 \%$ & $35.0 \%$ \\
\hline Median Ejection Fraction (Range) & & $48.0(10-75)$ & $50.0(17-72)$ & $45.0(15-75)$ \\
\hline Mortality in Hospital & 37 & $7.6 \%$ & $6.3 \%$ & $8.0 \%$ \\
\hline Mortality Within 1 Year & 62 & $12.7 \%$ & $9.4 \%$ & $15.3 \%$ \\
\hline
\end{tabular}

systems, and thus, suppression of common morning triggers of AMI may explain the absence of the circadian patterns in patients on beta-blockers and those with a history of diabetes mellitus. The absence of a circadian pattern in patients taking beta-blockers has been remarkably consistent overtime and between studies, with several other groups observing a complete loss of circadian pattern in patients taking betablockers. ${ }^{4,712,18}$ However, some have observed an attenuation or change in pattern, as opposed to complete loss. ${ }^{8,19}$ Results in diabetic patients are more variable. Similar to our findings, Fava et $\mathrm{al}^{20}$ and Sayer et $\mathrm{al}^{12}$ found the circadian pattern of AMI to be absent in patients with diabetes. However, others have observed an attenuated or altered pattern ${ }^{8,21}$ or even no effect of diabetes. ${ }^{18}$ These differences may be attributable to the inherent difficulties in studying diabetic patients, as the effects of diabetes on other health conditions are dependent on a number of factors including length of time the person has been afflicted, glycemic control, and medication use, among others. We were unable to capture detail regarding medication use, insulin-dependence, or diabetes duration in the present study. Future studies of diabetes and circadian patterns of AMI including such information may prove particularly interesting.

Other factors that attenuated, but did not abolish, the circadian pattern of STEMI occurrence in the present study include age, gender, statin use, and aspirin use. While attenuation of the circadian pattern in younger or female patients has not been reported previously, Gilpin et $\mathrm{al}^{8}$ did note a unique pattern of occurrence in older and female patients with equal peaks of occurrence in the morning and evening. Others have not observed any effect of age or gender. ${ }^{15,18}$ Attenuation of the circadian pattern in patients using statins and aspirin may be the result of the anti-inflammatory and anti-platelet properties of these medications, which may dampen the early morning triggers of AMI.

The circadian patterns of AMI onset observed in smokers also tend to vary by study. We did not observe attenuation of the pattern in smokers, rather a shift in the peak such that it occurred slightly earlier in smokers than in non-smokers. Hansen et $\mathrm{al}^{18}$ observed no effect of smoking, while Sayer et $\mathrm{al}^{12}$ observed a complete loss of the circadian pattern in smokers. Similar to our findings, Gilpin et $\mathrm{al}^{8}$ and Holmes et $\mathrm{al}^{17}$ observed changes in the pattern, but not loss. As with diabetes, the effects of smoking can also be difficult to study, as length of time as a smoker and packs per day can vary widely and may have an impact on the results.

In addition to examining factors that could modify the circadian pattern of STEMI occurrence, we also examined disease outcomes, including death, CHF, or stroke during initial hospital stay and over 1 year of follow-up. We observed no effect of time of STEMI onset on any outcomes. This finding is consistent with others which have shown that despite longer pre-hospital delays and longer time to treatment after arriving at the hospital in patients developing symptoms in the morning hours, there was no association between the circadian pattern of AMI onset and in-hospital death. ${ }^{17}$ 
The present study is limited by the retrospective nature of the data collection and use of subjective reports of time of chest pain onset. However, Willich et $\mathrm{al}^{46}$ demonstrated that selfreported pain onset correlated well with enzymatic confirmation. Additionally, our results are likely to be influenced by survival bias as patients who died at home or before reaching the hospital were not included. Subgroups of patients on beta-blockers, antiplatelet agents, and statins were small, which may have limited statistical power. However, findings are consistent with those in the literature.

\section{Conclusion}

Despite major medical advances and changes in lifestyle since the first reports of circadian patterns in AMI occurrence, we found that such a pattern still exists and that STEMI occurs most frequently in the morning hours. The circadian pattern of STEMI is absent, however, in patients on betablockers and with a history of diabetes mellitus and attenuated by several other medications and conditions.

\section{Acknowledgements}

The authors wish to thank Richard L. Berg, MS of the Marshfield Clinic Research Foundation's Biomedical Informatics Research Center for assistance with statistical analysis, and Rachel V. Stankowski, PhD of the Marshfield Clinic Research Foundation's Office of Scientific Writing and Publishing for assistance with preparation of the manuscript.

\section{References}

1. Roger VL, Go AS, Lloyd-Jones DM, Benjamin EJ, Berry JD, Borden WB, Bravata DM, Dai S, Ford ES, Fox CS, Fullerton HJ, Gillespie C, Hailpern SM, Heit JA, Howard VJ, Kissela BM, Kittner SJ, Lackland DT, Lichtman JH, Makuc DM, Marcus GM, Marellu A, Matchar DB, Moy CS, Mozaffarian D, Mussolino ME, Nichol G, Paynter NP, Soliman EZ, Sorlie PD, Sotoodehnia N, Turan TN, Virani SS, Wong ND, Woo D, Turner MB; American Heart Association Statistics Committee and Stroke Statistics Subcommittee. Executive summary: heart disease and stroke statistics-2012 update: a report from the American Heart Association. Circulation 2012;125:188-197.

2. Muller JE, Tofler GH, Stone PH. Circadian variation and triggers of onset of acute cardiovascular disease. Circulation 1989;79:733-743.

3. World Health Organization Regional Office for Europe. 1976. Myocardial infarction community registers: Results of a WHO international collaborative study coordinated by the Regional Office for Europe. Copenhagen: World Health Organization, Regional Office for Europe.

4. Muller JE, Stone PH, Turi ZG, Rutherford JD, Czeisler CA, Parker C, Poole WK, Passamani E, Roberts R, Robertson T, Sobel BE, Willerson JT, Braunwald E, and the MILIS Study Group. Circadian variation in the frequency of onset of acute myocardial infarction. New Engl J Med 1985;313:1315-1322.

5. Thompson DR, Blandford RL, Sutton TW, Marchant PR. Time of onset of chest pain in acute myocardial infarction. Int $\mathrm{J}$ Cardiol 1985;7:139-148.

6. Hjalmarson A, Gilpin EA, Nicod P, Dittrich H, Henning H, Engler R, Blacky AR, Smith SC Jr, Ricou F, Ross J Jr. Differing circadian patterns of symptom onset in subgroups of patients with acute myocardial infarction. Circulation 1989;80:267-275.
7. Willich SN, Linderer T, Wegscheider K, Leizorovicz A, Alamercery I, Schröder R. Increased morning incidence of myocardial infarction in the ISAM Study: absence with prior beta-adrenergic blockade. ISAM Study Group. Circulation 1989;80:853-858.

8. Gilpin EA, Hjalmarson A, Ross J Jr. Subgroups of patients with atypical circadian patterns of symptom onset in acute myocardial infarction. Am J Cardiol 1990;66:7G-11G.

9. Tofler GH, Muller JE, Stone PH, Forman S, Solomon RE, Knatterud GL, Braunwald E. Modifiers of timing and possible triggers of acute myocardial infarction in the Thrombolysis in Myocardial Infarction Phase II (TIMI II) Study Group. J Am Coll Cardiol 1992;20:1049-1055.

10. Kono T, Morita H, Nishina T, Fujita M, Hirota Y, Kawamura K, Fujiwara A. Circadian variations of onset of acute myocardial infarction and efficacy of thrombolytic therapy. J Am Coll Cardiol 1996;27:774-778.

11. Cohen MC, Rohtla KM, Lavery CE, Muller JE, Mittleman MA. Meta-analysis of the morning excess of acute myocardial infarction and sudden cardiac death. Am J Cardiol 1997;79:1512-1516.

12. Sayer JW, Wilkinson P, Ranjadayalan K, Ray S, Marchant B, Timmis AD. Attenuation or absence of circadian and seasonal rhythms of acute myocardial infarction. Heart 1997; 77:325-329.

13. Elliott WJ. Cyclic and circadian variations in cardiovascular events. Am J Hypertens 2001;14:291S-295S.

14. D'Negri CE, Nicola-Siri L, Vigo DE, Girotti LA, Cardinali DP. Circadian analysis of myocardial infarction incidence in an Argentine and Uruguayan population. BMC Cardiovasc Disord 2006;6:1.

15. Leiza JR, de Llano JM, Messa JB, Lopez CA, Fernandex JA; ARIAM Study Group. New insights into the circadian rhythm of acute myocardial infarction in subgroups. Chronobiol Int 2007;24:129-141.

16. Sari I, Davutoqlu V, Erer B, Tekbas E, Ucer E, Ozer O, Uyarel $\mathrm{H}$, Aksoy M. Analysis of circadian variation of acute myocardial infarction: afternoon predominance in Turkish population. Int J Clin Pract 2009;63:82-86.

17. Holmes DR, Aguirre FV, Aplin R, Lennon RJ, Nestler DM, Bell MR, Rihal CS, Ting HH. Circadian rhythms in patients with ST-elevation myocardial infarction. Circ Cardiovasc Qual Outcomes 2010;3:382-389.

18. Hansen O, Johansson BW, Gullberg B. Circadian distribution of onset of acute myocardial infarction in subgroups from analysis of 10,791 patients treated in a single center. Am J Cardiol 1992;69:1003-1008.

19. Garmendia-Leiza JR, Andres-de-Llano JM, Ardura-Fernandez J, Lopez-Messa JB, Alberola-Lopez C, Casaseca-Higuera P. Beta blocker therapy modifies circadian rhythm acute myocardial infarction. Int J Cardiol 2011;147:316-317.

20. Fava S, Azzopardi J, Muscat HA, Fenech FF. Absence of circadian variation in the onset of acute myocardial infarction in diabetic subjects. Br Heart J 1995;74:370-372.

21. Tanaka T, Fujita M, Fudo T, Tamaki S, Nohara R, Sasayama S Modification of the circadian variation of symptom onset of acute myocardial infarction in diabetes mellitus. Coron Artery Dis 1995;6:241-244.

22. Flegal KM, Carroll MD, Kit BK, Ogden CL. Prevalence of obesity and trends in the distribution of body mass index among US adults, 1999-2010. JAMA 2012;307:491-497.

23. National Center for Health Statistics. Health, United States, 2011: With Special Feature on Socioeconomic Status and Health. Hyattsville, MD. 2012.

24. Tsuda M, Hayashi H, Kanematsu K, Yoshikane M, Saito H. Comparison between diurnal distribution of onset of infarction in patients with acute myocardial infarction and circadian variation of blood pressure in patients with coronary artery disease. Clin Cardiol 1993;16:543-547. 
25. Fuster V, Dyken ML, Vokonas PS, Hennekens C. Aspirin as a therapeutic agent in cardiovascular disease. Special Writing Group. Circulation 1993;87:659-675.

26. Ballsi A, Raggi P, Merz CN, Shaw LJ. New insights into ischemic heart disease in women. Cleve Clin J Med 2007;74:585-594.

27. Turton MB, Deegan T. Circadian variations of plasma catecholamine, cortisol and immunoreactive insulin concentrations in supine subjects. Clin Chim Acta 1974;55:389-397.

28. Yasue H, Omote S, Takizawa A, Nagao M, Miwa K, Tanaka S. Circadian variation of exercise capacity in patients with Prinzmetal's variant angina: role of exercise-induced coronary arterial spasm. Circulation 1979;59:938-948.

29. Fujita M, Franklin D. Diurnal changes in coronary blood flow in conscious dogs. Circulation 1987;76:488-491.

30. Rosing DR, Brakman P, Redwood DR, Goldstein RE, Beiser GD, Astrup T, Epstein SE. Blood fibrinolytic activity in man. Diurnal variation and the response to varying intensities of exercise. Circ Res 1970;27:171-184.

31. Petralito A, Mangiafico RA, Gibiino S, Cuffari MA, Miano MF, Fiore CE. Daily modifications of plasma fibrinogen platelets aggregation, Howell's time, PTT, TT, and antithrombin II in normal subjects and in patients with vascular disease. Chronobiologia 1982;9;195-201.

32. Andreotti F, Davies GJ, Hackett DR, Khan MI, De Bart AC, Aber VR, Maseri A, Kluft C. Major circadian fluctuations in fibrinolytic factors and possible relevance to time of onset of myocardial infarction, sudden cardiac death and stroke. Am J Cardiol 1988;62:635-637.

33. Grimaudo V, Hauert J, Bachmann F, Kruithof EK. Diurnal variation of the fibrinolytic system. Thromb Haemost 1988;59:495-499.

34. Huber K, Rosc D, Resch I, Schuster E, Glogar DH, Kaindl F, Binder BR. Circadian fluctuations of plasminogen activator inhibitor and tissue plasminogen activator levels in plasma of patients with unstable coronary artery disease and acute myocardial infarction. Thromb Haemost 1988;60:372-376.

35. Angleton P, Chandler WL, Schmer G. Diurnal variation of tissue-type plasminogen activator and its rapid inhibitor (PAI-1). Circulation 1989;79:101-106.

36. Bridges AB, McLaren M, Scott NA, Pringle TH, McNeill GP, BelchJJ. Circadian variation of tissue plasminogen activator and its inhibitor, von Willebrand factor antigen, and prostacyclin stimulating factor in men with ischaemic heart disease. Br Heart J 1993;69:121-124.

37. Masuda T, Ogawa H, Miyao Y, Yu Q, Misumi I, Sakamoto T, Okubo H, Okumura K, Yasue H. Circadian variation in fibrinolytic activity in patients with variant angina. Br Heart J 1994;71:156-161.

38. Ehrly AM, Jung G. Circadian rhythm of human blood viscosity. Biorheology 1973;10:577-583.

39. Brezinski DA, Tofler GH, Muller JE, Pohjola-Sintonen S, Willich SN, Schafer AI, Czeisler CA, Williams GH. Morning increase in platelet aggregability. Association with assumption of the upright posture. Circulation 1988;78, $35-40$.

40. Kawahara J, Sano H, Fukuzaki H, Saito K, Hirouchi H. Acute effects of exposure to cold on blood pressure, platelet function and sympathetic nervous activity in humans. Am J Hypertens 1989;2:724-726.

41. Reis DJ. Potentiation of the vasoconstrictor action of topical norepinephrine on the human bulbar conjuctival vessels after topical application of certain adrenocortical hormones. J Clin Endocrinol Metab 1960;20:446-456.

42. Weitzman ED, Fukushima D, Nogeire C, Roffwarg H, Gallagher TF, Hellman L. Twenty-four hour pattern of the episodic secretion of cortisol in normal subjects. J Clin Endocrinol Metab 1971;33:14-22.
43. Leibetseder V, Humpeler S, Svoboda M, Schmid D, Thalhammer T, Zuckermann A, Marktl W, Ekmekcioqlu C. Clock genes display rhythmic expression in human hearts. Chronobiol Int 2009;26:621-636.

44. Rocco MB, Nabel EG, Selwyn AP. Circadian rhythms and coronary artery disease. Am J Cardiol 1987;59:13C-17C.

45. Mittleman MA, Maclure M, Tofler GH, Sherwood JB, Goldberg RJ, Muller JE. Triggering of acute myocardial infarction by heavy physical exertion. Protection against triggering by regular exertion. Determinants of Myocardial Infarction Onset Study Investigators. New Engl J Med 1993;329:677-683.

46. Willich SN, Lewis M, Löwel H, Arntz HR, Schubert F, Schröder R. Physical exertion as a trigger of acute myocardial infarction. Triggers and Mechanisms of Myocardial Infarction Study Group. N Engl J Med 1993;329:1684-1690.

47. Sayer JW, Gutteridge C, Syndercombe-Court D, Wilkinson P, Timmis AD. Circadian activity of the endogenous fibrinolytic system in stable coronary artery disease: effects of betaadrenoreceptor blockers and angiotensin-converting enzyme inhibitors. J Am Coll Cardiol 1998;32:1962-1968.

48. Goldstein JA, Demetriou D, Grines CL, Pica M, Shoukfeh M, O'Neill WW. Multiple complex coronary plaques in patients with acute myocardial infarction. N Engl J Med 2000;343:915-922.

49.Smolensky MH, Hermida RC, Portaluppi F, Haus E. Twentyfour-hour pattern of angina pectoris, acute myocardial infarction and sudden cardiac death: Role of blood pressure, heart rate and rate-pressure product circadian rhythms. Biol Rhythm Res 2007;38:205-216.

\section{Author Affiliations}

Rajan Kanth, $M D^{*}$; Sunitha Ittaman, $M D^{*}$; Shereif Rezkalla, $M D, F A C P^{*}$

*Department of Internal Medicine, Marshfield Clinic, Marshfield, WI USA

'Department of Cardiology, Marshfield Clinic, Marshfield, WI USA 